\section{Some Statistical Aspects of Blood Sugar Regulation}

In the examination of physiological regulations we are often concerned with averages observed on successive occasions with short time-intervals. Other statistical parameters could be also used, since they throw some light on regulatory mechanisms. This can be shown by the following results.

Long-term reliability of fasting blood sugar-level is very low $(r=0.32)$, but if the time elapsed between the first and the second taking of blood is short (about $1 \mathrm{~h}$ ) correlation appears to be relatively high: $r=0 \cdot 79$. This figure has been obtained on fasting men at rest. If before the second blood-letting they were made to walk on a treadmill ( $15 \mathrm{~min}$ at $7 \mathrm{~km} / \mathrm{h}$ ), averages did not change, but the correlation between the successive blood sugar-levels determined with the same time-interval fell to 0.57 . Therefore something happened which was not reflected by averages, but interfered with correlations.

If $r=0$, blood sugar variations on successive occasions would be completely independent and no regulatory influence for a given time-interval could be supposed. If $r>0$, it has no obvious meaning: it may be due to regulatory activity or to passive maintenance of the same blood. sugar-level during a short period. But if correlations betweon successive occasions change in an orderly way, their variations may be meaningful.

Tables $\mathrm{I}$ and 2 show what happens with half-hourly intervals after absorption of glucose $(30 \mathrm{~g})$.

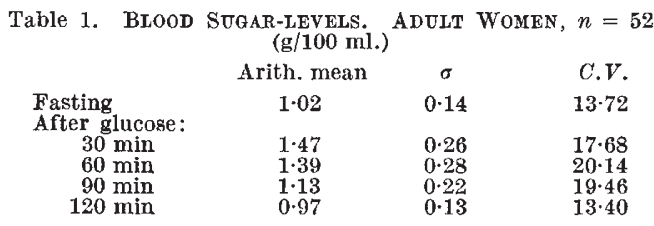

Table 2. Correlations BETWEen Blood SUGAR-LeVels

\begin{tabular}{lrccccc}
\multicolumn{7}{c}{ ADULT WOMEN, $n=52$} \\
\\
& Fasting & 1 & 2 & 3 & 4 & 5 \\
1 & - & 0.25 & 0.05 & 0.25 & 0.51 \\
2 & $30 \mathrm{~min}$ & & - & 0.55 & 0.38 & 0.37 \\
3 & $60 \mathrm{~min}$ & & & - & 0.67 & 0.43 \\
4 & $90 \mathrm{~min}$ & & & & - & 0.77 \\
5 & $120 \mathrm{~min}$ & & & & & -
\end{tabular}

Half an hour after a glucose meal, blood sugar-level attains its highest average. Absolute and relative variabilities rise simultaneously and the correlation with the fasting-level appears to be very low, much lower indeed than short-term fasting reliability. After $1 \mathrm{~h}$ the average begins to decrease whereas both variabilities are at their peak value. Thereafter, averages and variabilities decrease simultaneously. There is an increase of 'disorder' followed by a progressive decrease.

Correlations grouped in Table 2 have two prominent features. In the upper row, correlations between fastinglevel and after-glucose-levels disappear at the 60th min, then rise again, and the last figure is twice as great as the first one and is significant. On the other hand, figures in the lowest diagonal show that correlations between successive blood sugar-levels, beginning with a very low value, rise steadily and at the end wo find a coefficient as high as fasting short-term reliability.

The steady increase of correlations in the lowest diagonal probably reflects the growing efficiency of regulatory process. In the upper row the disappearance of the correlation between the fasting and after-glucose level at the 60 th $\mathrm{min}$, followed by a remarkable riso, means that after a break there is a tendency to restore the initial fasting-level. Nevertheless, even after $2 \mathrm{~h}$ this result is not completely achieved: in column 5 , the first figure is still lower than the last one which, as I have alroady pointed out, is as high as fasting reliability.

Moreover, in Table 1 the last average is lower than the first; the difference is small, but significant. A similar difference has been observed more than once, and some authors, in order to define the fall of the last observed value below the fasting-level, used words such as 'hypercorrection'. This word soems to mean that physiological regulations should in all circumstances restore a fixed 'normal' valuo. If for some reason they cannot 'correct', at least they must 'hypercorrect' the departure from the 'normal' point.

In accordance with some other results my figures have a less-metaphysical meaning. The comparison of averages, variabilities and correlations show that $2 \mathrm{~h}$ after a glucose moal a new slightly different orderliness is attained. This may be explained in many ways, which are not alternative.

The fall of blood sugar-level below the fasting value can bo due to the fact that $2 \mathrm{~h}$ after a glucose meal the subjects are still hungry. The same fall has been observed twice in fasting men at rest as well as after a tread-mill walk (first average: $0.95 \mathrm{~g} / 100 \mathrm{ml}$.; second average: 0.90 ). Perhaps this small difference can be explained also by psychological interferences, the first blood-letting being apparently feared more than the second or the third. If this is so, 'normal' values, usually represented by the first fasting-level, may be a littlo exaggerated by emotive hyporglycamia.

We cannot standardize either laboratory animals or human subjects. Alimentary habits, activities preceding the test and possible psychological perturbations are seldom taken into account. Of course, it would be difficult to ascertain them in every case. Therefore, we are left with an unavoidable margin of uncertainty. Nevertheless, my figures agree with conclusions already suggested by the examination of intra-individual variability ${ }^{1}$. In fact, the living organism is never in equilibrium, but struggling for it. In continuously changing situations physiological regulations tend to maintain a limited (statistical) orderliness, not necessarily to restore the previous one.

Laboratoire d'Anthropologie Physique.

Eugéne SChreider

Ecole des Hautes Etudes et Laboratoire de Biométrie Humaine,

Centre National de la Recherche Scientifique, Paris.

${ }^{1}$ Schreider, E., Les règulations physiologiques, Essai de révision biométrique du problème de l'homéostasie (Office Intern. Documentation et Librairic, Paris, 1958).

\section{PHARMACOLOGY}

\section{Thymectomy in Dogs with Renal Homografts treated with Drugs}

MILLER $\mathbf{R}^{1}$ has reported an additive effect of $\mathbf{X}$-irradiation and thymectomy in depressing immunological mechanisms in adult animals. Accordingly an investigation was undertaken to determine whether thymectomy improved the functional survival of homologous renal transplants in dogs treated with drugs.

The experimental preparation and assessment of results were identical to that reported previously elsewhere ${ }^{2}$. Using pentobarbitone anæsthesia with air-insufflation of the lungs, the thymus was removed from mongrel dogs of either sex, via a right thoracotomy through the second inter-space. At the same time, a kidney from an unrelated dog was transplanted to the right iliac fossa and the animal's own two kidneys were removed. The drugs were administered as follows: actinomycin $C(10 \mathrm{r} / \mathrm{kg})$ intravenously on the day of operation and at weekly intervals. 6-mercaptopurine suspension $5 \mathrm{mg} / \mathrm{kg}$ intramuscularly on the day of operation, followed by 'Imuran' daily by mouth, $10 \mathrm{mg} / \mathrm{kg}$ on the first and second day after operation and $5 \mathrm{mg} / \mathrm{kg}$ on subsequent days. The dose was reduced if the total white cell count fell below 5,000 cells $/ \mathrm{mm}^{3}$. This drug combination has been found previously to be effective in prolonging canine renal homograft survival ${ }^{2}$. 